\title{
On the asymptotic uniqueness of bargaining equilibria
}

Citation for published version (APA):

Herings, P. J. J., \& Predtetchinski, A. (2010). On the asymptotic uniqueness of bargaining equilibria. METEOR, Maastricht University School of Business and Economics. METEOR Research Memorandum No. 010 https://doi.org/10.26481/umamet.2010010

Document status and date:

Published: 01/01/2010

DOI:

10.26481/umamet.2010010

Document Version:

Publisher's PDF, also known as Version of record

\section{Please check the document version of this publication:}

- A submitted manuscript is the version of the article upon submission and before peer-review. There can be important differences between the submitted version and the official published version of record.

People interested in the research are advised to contact the author for the final version of the publication, or visit the DOI to the publisher's website.

- The final author version and the galley proof are versions of the publication after peer review.

- The final published version features the final layout of the paper including the volume, issue and page numbers.

Link to publication

\footnotetext{
General rights rights.

- You may freely distribute the URL identifying the publication in the public portal. please follow below link for the End User Agreement:

www.umlib.nl/taverne-license

Take down policy

If you believe that this document breaches copyright please contact us at:

repository@maastrichtuniversity.nl

providing details and we will investigate your claim.
}

Copyright and moral rights for the publications made accessible in the public portal are retained by the authors and/or other copyright owners and it is a condition of accessing publications that users recognise and abide by the legal requirements associated with these

- Users may download and print one copy of any publication from the public portal for the purpose of private study or research.

- You may not further distribute the material or use it for any profit-making activity or commercial gain

If the publication is distributed under the terms of Article $25 \mathrm{fa}$ of the Dutch Copyright Act, indicated by the "Taverne" license above, 


\section{Maastricht University}

P. Jean J acques Herings, Arkadi Predtetchinski

On the Asymptotic Uniqueness of Bargaining Equilibria

$\mathrm{RM} / 10 / 010$

\section{METEOR}

Maastricht University School of Business and Economics

Maastricht Research School of Economics

of Technology and Organization

P.O. Box 616

NL - 6200 MD Maastricht

The Netherlands 


\title{
On the Asymptotic Uniqueness of Bargaining Equilibria
}

\author{
P. Jean-Jacques Herings and Arkadi Predtetchinski* \\ February 19, 2010
}

\begin{abstract}
This note reexamines the connection between the asymmetric Nash bargaining solution and the equilibria of strategic bargaining games. Several papers in the literature obtain the asymmetric Nash bargaining solution as the unique limit of subgame perfect equilibria in stationary strategies when the breakdown probability approaches zero. This note illustrates by means of two examples that this result depends crucially on the differentiability of the boundary of the set of feasible payoffs. In the first example the game has a unique stationary subgame perfect equilibrium that fails to converge to the asymmetric Nash bargaining solution. In the second example the game has two stationary subgame perfect equilibria that converge to two distinct limits as the breakdown probability vanishes. This example demonstrates that without differentiability of the set of feasible payoffs there is not even asymptotic uniqueness of stationary equilibria in the bargaining model.
\end{abstract}

JEL classification codes: C78.

Keywords: Bargaining, Nash bargaining solution, subgame perfect equilibrium, stationary strategies, multiplicity of equilibrium.

*Department of Economics, Maastricht University, P.O. Box 616, 6200 MD Maastricht, The Netherlands. E-mail: P.Herings@maastrichtuniversity.nl, A.Predtetchinski@maastrichtuniversity.nl. The authors acknowledge the financial support of the Netherlands Organisation for Scientific Research (NWO). 


\section{Introduction}

The theory of non-cooperative bargaining has resulted in a substantial body of research following the seminal contribution of Rubinstein (1982). We are interested in the generalization of this model to the case with $n$ players. The main characteristics of the model are that $n$ players bargain about an $n$-dimensional convex set of feasible payoffs, decision making requires the consent of all the players involved, and bargaining takes place in an alternating offers style. At the beginning of each period, some player is selected as the proposer and makes a proposal, followed by an accept or reject decision of the other players. In case of rejection by at least one player, there is some probability that negotiations break down. Otherwise, bargaining proceeds in the next period with the selection of a new proposer, and so on, and so forth.

The existence of a subgame perfect equilibrium in stationary strategies in this model follows from the results of Banks and Duggan (2000). A number of papers shows, under increasingly weaker assumptions, that in the limit, when the breakdown probability converges to zero, the equilibrium converges to the Nash bargaining solution. Binmore, Rubinstein, and Wolinsky (1986) show that the unique subgame perfect equilibrium of the 2-player game of bargaining with alternating offers as in Rubinstein (1982) converges to the Nash bargaining solution as the time interval between two consecutive rounds of bargaining vanishes. The stationary subgame perfect equilibria in the bargaining procedure of Hart and Mas-Colell (1996) converge to the Nash bargaining solution in the $n$-player case when applied to the special case where decision making requires unanimous approval, and Kultti and Vartiainen (2007) show convergence to the Nash bargaining solution for the $n$-player case when players rotate in making offers.

Miyakawa (2006), Laruelle and Valenciano (2008), Britz, Herings, and Predtetchinski (2008) give a non-cooperative foundation for the asymmetric Nash bargaining solution in the case of $n$ players. Miyakawa (2006) and Laruelle and Valenciano (2008) consider a bargaining game with time-invariant recognition probabilities and show that, as the probability of breakdown of negotiations becomes small, the stationary subgame perfect equilibria approach the asymmetric Nash bargaining solution, with the weights corresponding to the players' recognition probabilities. Britz, Herings and Predtetchinski (2008) establish a similar convergence result in a game where the selection of the proposer is determined by a Markov process, thereby covering both time-invariant recognition probabilities and rotating offers as special cases. The weights in the asymmetric Nash bargaining solution are now given by the probabilities of the stationary distribution of the proposer selection process.

Such convergence results are desirable for at least two reasons. They imply that bargaining equilibria are asymptotically unique and that it is rather straightforward to compute what the limit equilibrium looks like. Apart from asymptotic uniqueness of bargaining equilibrium, there are few general uniqueness results for the $n$-player case with unanimous approval. The main result is in Merlo and Wilson (1995), who show that bargaining equilibria are unique when the best response function has a contraction property. The contraction property is shown to hold when the set of feasible payoffs is derived from linear 
utility functions, or from separable concave utility functions with deterministically chosen proposers.

All the papers on multilateral bargaining that give convergence results to the Nash bargaining solution do so under the assumption that the convex set of feasible payoffs has a boundary that is non-level and differentiable. The non-levelness of the boundary means that each weakly Pareto-efficient payoff vector is also Pareto efficient. The assumption of differentiability of the boundary means that the normal vector to the set of feasible payoffs is unique up to a multiplier. Since general convex sets of feasible payoffs can be approximated by differentiable ones, one may conjecture that the asymptotic uniqueness of bargaining equilibria and their convergence to the Nash bargaining solution carries over to the general convex case. This intuition is reinforced by the fact that a general result holds for the case with two players.

Nevertheless, this note demonstrates that the differentiability assumption is crucial. To do so we construct two examples with three players where the payoff set satisfies all of the standard assumptions except for the differentiability assumption. The main feature of our first example is that the unique stationary subgame perfect equilibrium does not converge to the Nash bargaining solution. A similar example, though not satisfying non-levelness, was developed independently in Kultti and Vartiainen (2007). The main feature of the second example is that there are two distinct stationary subgame perfect equilibria that converge to different limits as the breakdown probability becomes small. This example therefore shows that the uniqueness result of Merlo and Wilson (1995) does not hold for general convex sets of feasible payoffs and that asymptotic uniqueness of bargaining equilibria may fail when the set of feasible payoffs has a non-differentiable boundary.

These findings are particularly surprising in light of the existing literature on onedimensional bargaining. In a one-dimensional bargaining model the players negotiate over the choice of an alternative represented by a point in an interval. In such a game the set of attainable payoffs is one-dimensional and therefore is neither comprehensive nor convex. The asymptotic uniqueness of stationary equilibria has been established for a number of variations of the one-dimensional model of bargaining, see Cho and Duggan (2003), Cardona and Ponsatí (2007), Predtetchinski (2007), and Herings and Predtetchinski (2009). In the one-dimensional model, for asymptotic uniqueness, it is important that utility functions be continuous and concave, but may well have points of non-differentiability. Nondifferentiability of utility functions gives rise to a kink in the set of feasible payoffs, but this does not destroy the asymptotic uniqueness of stationary equilibria. This is in contrast to the examples presented in this paper, which show that when the set of payoffs is convex and comprehensive, the kinks may well lead to asymptotic multiplicity of equilibria.

\section{The Bargaining Game}

Given a continuation probability $\delta \in[0,1)$, define the $n$-player bargaining game $\Gamma(\delta)$ as follows. The game starts in period zero. At the beginning of each period one of the players is randomly drawn to make a proposal. Player $i$ is chosen with probability $\mu_{i}>0$. The 
chosen player proposes an alternative $x$ from the set $V$ of feasible payoffs. All players (including the proposer) respond sequentially, with the sequence of responses being fixed throughout the game. Each responder can either accept or reject the current proposal. If all players accept the proposal, the game terminates and the proposal $x$ is implemented, with player $i$ receiving a payoff of $x_{i}$. Otherwise, the next period begins with probability $\delta$, whereas negotiations break down with probability $1-\delta$.

(A1) The set $V$ is a closed, convex, and proper subset of $\mathbb{R}^{n}$ containing the point 0 in its interior.

(A2) The set $V$ is comprehensive from below: If $x \in V$ and $y \in \mathbb{R}^{n}$ are such that $y_{i} \leq x_{i}$ for each $i$, then $y \in V$.

(A3) The boundary $\partial V$ of the set $V$ is non-level: If $x$ and $y$ are points of $\partial V$ such that $x_{i} \leq y_{i}$ for each $i=1, \ldots, n$, then $x=y$.

We shall restrict our attention to pure stationary strategies by which we mean strategies such that (a) the proposal of any player is independent of the history of play and (b) the response of a player to a proposal only depends on the proposal itself. Thus a stationary strategy of player $i$ consists of a proposal $p_{i} \in V$ and an acceptance set $A_{i} \subset V$. Player $i$ proposes the point $p_{i}$ whenever player $i$ is chosen to be a proposer and he accepts a proposal $x$ if and only if $x$ is an element of the set $A_{i}$. Theorems 1 and 2 below are well-known results.

Theorem 1 Suppose (A1)-(A3) are satisfied. Each subgame perfect equilibrium of the game $\Gamma(\delta)$ in stationary strategies is a no-delay equilibrium. That $i s, p_{i} \in \cap_{j=1}^{n} A_{j}$ for each $i=1, \ldots n$.

Since each equilibrium proposal is implemented without delay, the expected payoffs in a stationary subgame perfect equilibrium can be computed as $r=\mu_{1} p_{1}+\cdots+\mu_{n} p_{n}$. Furthermore, the expected payoff to any player in any Nash equilibrium of $\Gamma(\delta)$ is nonnegative, since a player can attain a payoff of zero by rejecting all proposals.

Theorem 2 Suppose (A1)-(A3) are satisfied. Let $p_{1}, \ldots, p_{n}$ be points of $V$. There exists a subgame perfect equilibrium of the game $\Gamma(\delta)$ in stationary strategies with $p_{i}$ the equilibrium proposal of player $i$ if and only if each $p_{i}$ is an element of $\partial V$ and there exists a vector $r$ such that for each $i$ and $j$

$$
p_{i j}= \begin{cases}\frac{1-\delta+\delta \mu_{i}}{\mu_{i}} r_{i} & \text { if } i=j \\ \delta r_{j} & \text { otherwise. }\end{cases}
$$

The vector $r$ in Theorem 2 coincides with the vector of expected payoffs.

We now turn to the asymptotic behavior of stationary subgame perfect equilibria as the continuation probability approaches one. Theorem 3 below shows that, under a differentiability assumption on the set $V$, the subgame perfect equilibria in stationary strategies 
are asymptotically unique: along any sequence of stationary subgame perfect equilibria as $\delta$ tends to one, the equilibrium proposal of each player converges to the asymmetric Nash bargaining solution.

The asymmetric Nash product with weights $\mu$ is the function $\rho: V \longrightarrow \mathbb{R}$ defined by

$$
\rho(x)=\times_{i=1}^{n}\left(x_{i}\right)^{\mu_{i}} .
$$

The point $x$ of $V$ is the asymmetric Nash bargaining solution with weights $\mu$ ( $\mu$-ANBS) if it maximizes the function $\rho$ on the set $V$. Theorem 3 relies on the additional assumption of differentiability of the boundary of the set $V$.

(A4) The normal vector to $V$ is unique up to a multiplier at any $v \in \partial V$. Equivalently, the set $\partial V$ is a $C^{1}$-manifold.

Theorem 3 Suppose (A1)-(A4) are satisfied. Let $\delta^{k} \in[0,1)$ be a sequence of continuation probabilities converging to 1 . For each $k$ let $\left(p_{1}^{k}, \ldots, p_{n}^{k}\right)$ be the players' proposals in a stationary subgame perfect equilibrium of the game $\Gamma\left(\delta^{k}\right)$. As $k$ goes to infinity each sequence $p_{i}^{k}$ converges to the asymmetric Nash bargaining solution with weights $\mu$.

This result has been established by Hart and Mas-Colell (1996) in the case of equal recognition probabilities, Miyakawa (2006), Laruelle and Valenciano (2008), and Britz, Herings, and Predtetchinski (2008). We remark that when $n=2$ the conclusion of Theorem 3 is true under the assumptions (A1)-(A3). For the two-player game where proposers are chosen with equal probability, Binmore, Rubinstein, and Wolinsky (1986) show the convergence of equilibria to the symmetric Nash bargaining solution. There is no difficulty in extending this result to the case with general recognition probabilities $\mu$.

\section{Two Examples}

We give two examples highlighting the role of the differentiability assumption (A4) for the asymptotic uniqueness of equilibria. Both examples satisfy Assumptions (A1)-(A3) but not (A4). The main feature of the example in Subsection 3.1 is that the game $\Gamma(\delta)$ has a unique stationary subgame perfect equilibrium for each continuation probability, but the equilibria converge to a point different from the asymmetric Nash bargaining solution. A similar example, not satisfying (A3), has been developed independently in Kultti and Vartianen (2007). The main feature of the example in Subsection ?? is the asymptotic multiplicity of equilibria: for each $\delta$ the game $\Gamma(\delta)$ has at least two distinct equilibria converging to two distinct limits as the continuation probability tends to one.

\subsection{Equilibria do not converge to ANBS}

Consider a 3 -player game with recognition probabilities $\mu_{i}=1 / 3$ for each $i$. The set $V$ is the intersection of two halfspaces as depicted in Figure ??:

$$
V=H_{1} \cap H_{2},
$$


where

$$
\begin{aligned}
& H_{1}=\left\{x \in \mathbb{R}^{n} \mid 2 x_{1}+x_{2}+3 x_{3} \leq 15\right\}, \\
& H_{2}=\left\{x \in \mathbb{R}^{n} \mid x_{1}+2 x_{2}+3 x_{3} \leq 15\right\} .
\end{aligned}
$$

By Theorem 2 the equilibrium proposals are related to the expected payoffs $r$ as depicted in the following table.

$$
\begin{array}{c|ccc}
p_{1} & (3-2 \delta) r_{1} & \delta r_{2} & \delta r_{3} \\
p_{2} & \delta r_{1} & (3-2 \delta) r_{2} & \delta r_{3} \\
p_{3} & \delta r_{1} & \delta r_{2} & (3-2 \delta) r_{3}
\end{array}
$$

Table 1: Equilibrium proposals.

The equilibrium proposal of each player lies in the boundary of the set $V$. A point $x \in \mathbb{R}^{n}$ belongs to the boundary of the set $V$ if and only if $h(x)=15$, where the function $h$ is defined by

$$
h(x)=\max \left\{x_{1}+2 x_{2}+3 x_{3}, 2 x_{1}+x_{2}+3 x_{3}\right\}=x_{1}+x_{2}+3 x_{3}+\max \left\{x_{1}, x_{2}\right\} .
$$

Therefore

$$
\begin{aligned}
& 15=h\left(p_{1}\right)=(3-2 \delta) r_{1}+\delta r_{2}+3 \delta r_{3}+\max \left\{(3-2 \delta) r_{1}, \delta r_{2}\right\} \\
& 15=h\left(p_{2}\right)=\delta r_{1}+(3-2 \delta) r_{2}+3 \delta r_{3}+\max \left\{\delta r_{1},(3-2 \delta) r_{2}\right\} \\
& 15=h\left(p_{3}\right)=\delta r_{1}+\delta r_{2}+3(3-2 \delta) r_{3}+\max \left\{\delta r_{1}, \delta r_{2}\right\}
\end{aligned}
$$

Subtracting the first equation from the second we obtain

$$
3(1-\delta) r_{1}+\max \left\{(3-2 \delta) r_{1}, \delta r_{2}\right\}=3(1-\delta) r_{2}+\max \left\{\delta r_{1},(3-2 \delta) r_{2}\right\} .
$$

Now suppose $r_{1}<r_{2}$. Then $\max \left\{(3-2 \delta) r_{1}, \delta r_{2}\right\}<(3-2 \delta) r_{2} \leq \max \left\{\delta r_{1},(3-2 \delta) r_{2}\right\}$, implying that the left-hand side of the above equation is smaller than the right-hand side, a contradiction. Similarly, one shows that $r_{2}<r_{1}$ is impossible. We have thus established that $r_{1}=r_{2}$. The system above reduces to the following:

$$
\begin{aligned}
& 15=3(2-\delta) r_{1}+3 \delta r_{3} \\
& 15=3 \delta r_{1}+3(3-2 \delta) r_{3} .
\end{aligned}
$$

Solving the system, we obtain the following values for the expected payoffs:

$$
\left(r_{1}, r_{2}, r_{3}\right)=(15,15,10) /(6-\delta) \text {. }
$$

As $\delta$ tends to one, the expected values converge to the vector $(3,3,2)$. It is clear that also the equilibrium proposal of each player converges to the point $(3,3,2)$. The asymmetric Nash bargaining solution can be easily computed to be $(10 / 3,10 / 3,5 / 3)$. Thus the unique equilibrium of the game $\Gamma(\delta)$ fails to converge to the asymmetric Nash bargaining solution as $\delta$ tends to one. 


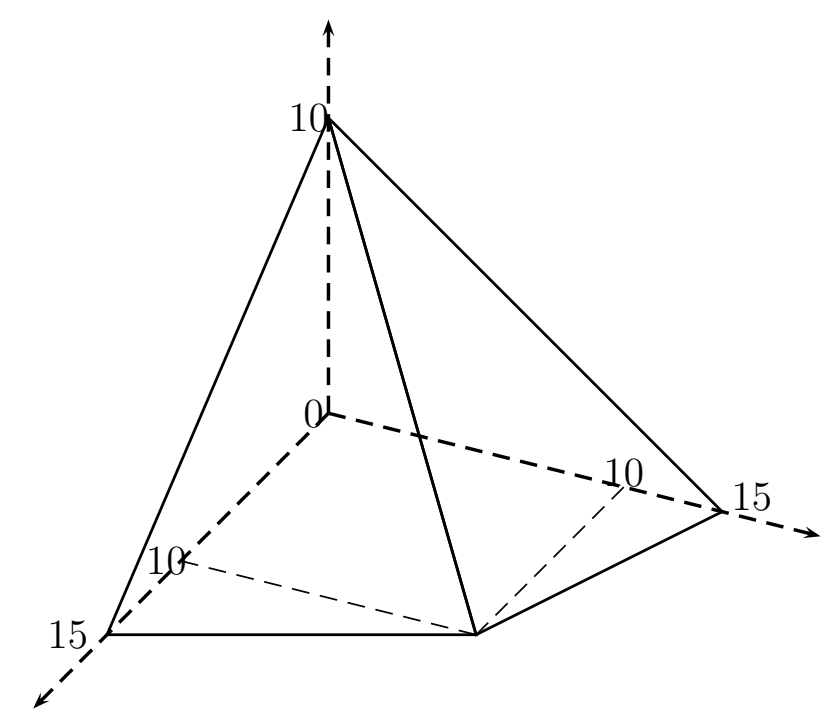

Figure 1: The set $V$ in the example of Subsection 3.1. The vertical axis represents the payoff to player 3 .

\subsection{Asymptotic multiplicity of equilibria}

Consider a 3 -player game with recognition probabilities $\mu_{i}=1 / 3$ for each $i$. The set of feasible payoffs, denoted by $W$, is the intersection of the set $V$ as defined in the previous subsection and the halfspace $H_{3}$ :

$$
W=V \cap H_{3},
$$

where

$$
H_{3}=\left\{x \in \mathbb{R}^{n} \mid(2-5 \varepsilon) x_{1}+(2-5 \varepsilon) x_{2}+(3+4 \varepsilon) x_{3} \leq 3(2-5 \varepsilon)(3+4 \varepsilon)\right\},
$$

and $\varepsilon \in(0,1 / 60)$. We show that for $\delta$ large enough the game $\Gamma(\delta)$ has multiple equilibria. Moreover, one equilibrium converges to the point $(3,3,2)$ and the other one to the point $(3+4 \varepsilon, 3+4 \varepsilon, 2-5 \varepsilon)$.

Equilibrium 1. We argue that the equilibrium of the game with set of utilities $V=$ $H_{1} \cap H_{2}$ as considered in the preceding section remains an equilibrium in the game $W$ for $\delta$ large enough. In fact, using Theorem 2 we only have to verify that the players' proposals $p_{1}, p_{2}$ and $p_{3}$ in the bargaining equilibrium of the game $V$ belong to the half- space $H_{3}$. To see this recall that the proposals $p_{1}, p_{2}$ and $p_{3}$ converge to the point $v=(3,3,2)$. The point $v$ belongs to the interior of the half-space $H_{3}$ provided that $0<\varepsilon<1 / 60$. But this implies that the proposals $p_{1}, p_{2}$ and $p_{3}$ lie in the half-space $H_{3}$ for $\delta$ large enough, as desired.

Equilibrium 2. Consider first the game where the set of feasibly utilities is the entire half-space $H_{3}$. It follows from the results in Merlo and Wilson (1995) that such a game has a unique bargaining equilibrium, and that the equilibrium proposal of each player converges to the Nash bargaining solution of $H_{3}$ as $\delta$ tends to 1 . The Nash bargaining solution of $H_{3}$ is the point $w=(3+4 \varepsilon, 3+4 \varepsilon, 2-5 \varepsilon)$.

Let $\bar{p}_{i}$ be the equilibrium proposal of player $i$ in the bargaining equilibrium of $H_{3}$. We argue that the bargaining equilibrium of the game $H_{3}$ is also an equilibrium of the game 
$W$. In fact, using Theorem 2 one only has to verify that the players' proposals $\bar{p}_{i}$ all belong to the half-spaces $H_{1}$ and $H_{2}$. The point $w$ can be seen to be in the interior of both half-spaces $H_{1}$ and $H_{2}$ provided that $\varepsilon>0$. It follows that for $\delta$ large enough the players' proposals $\bar{p}_{i}$ also belong to the half-spaces $H_{1}$ and $H_{2}$, as desired.

\section{References}

[1] Jeff Banks And John DugGan : A Bargaining Model of Collective Choice. American Political Science Review, 94: 73-88, 2000.

[2] Ken Binmore, Ariel Rubinstein, and Asher Wolinsky: The Nash Bargaining Solution in Economic Modelling. The RAND Journal of Economics, 17: 176-188, 1986.

[3] Volker Britz, P. Jean-Jacques Herings, and Arkadi Predtetchinski: Non-cooperative Support for the Asymmetric Nash Bargaining Solution. METEOR Research Memorandum RM/08/018, pp. 1-21, 2008. Forthcoming in Journal of Economic Theory.

[4] Daniel Cardona And Clara Ponsatí: Bargaining One-dimensional Social Choices. Journal of Economic Theory, 137: 627-651, 2007.

[5] Seok-Ju Cho and John Duggan: Uniqueness of Stationary Equilibria in a Onedimensional Model of Bargaining. Journal of Economic Theory, 113: 118-130, 2003.

[6] Sergiu Hart and Andreu Mas-Colell: Bargaining and Value. Econometrica, 64: 357-380, 1996.

[7] P. Jean-Jacques Herings and Arkadi Predtetchinski: One-dimensional bargaining with Markov recognition probabilities. Journal of Economic Theory, 145: 189-215, 2010.

[8] Klaus Kultti and Hannu Vartiainen: Multilateral Non-Cooperative Bargaining in a General Utility Space. Working Paper, pp. 1-15.

[9] Annick Laruelle and Federico Valenciano: Noncooperative Foundations of Bargaining Power in Committees and the Shapley-Shubik Index. Games and Economic Behavior, 63: 341-353, 2008.

[10] Antonio Merlo and Charles Wilson: A Stochastic Model of Sequential Bargaining with Complete Information. Econometrica, 63: 371-399, 1995.

[11] Toshiji Miyakawa: Non-cooperative Foundation of $n$-Person Asymmetric Nash Bargaining Solution. Osaka University of Economics, Working Paper No. 2006-2. 
[12] Arkadi Predtetchinski: One-dimensional Bargaining with a General Voting Rule. METEOR Research Memorandum 07/045, Maastricht University, 2007.

[13] Ariel Rubinstein: Perfect Equilibrium in a Bargaining Model. Econometrica, 50: 97-109, 1982. 